\title{
INTRAOCULAR LENS IMPLANTATION IN CHILDREN IN THE WEST BANK AND GAZA
}

\author{
CHARLIE A. KANAWATI \\ East Jerusalem
}

\begin{abstract}
SUMMARY
In order to evaluate the efficacy and safety of intraocular lens (IOL) implantation in paediatric aphakia, we reviewed the records of a consecutive series of 40 children, under 15 years of age, who had IOLs inserted for congenital and developmental cataracts between September 1990 and December 1992. Visual results and lens-induced complications were evaluated in 67 eyes with a mean follow-up of 27 months (range 12-38 months). In 52 eyes the cataract was removed by limbal lens aspiration and in 15 eyes by pars plicata lens aspiration. One-piece PMMA Sinskeytype posterior chamber implants were used in all cases. Sixty-three eyes had primary and 4 eyes secondary implants. Seventeen (49\%) of 35 eyes with congenital cataract and $25(78 \%)$ of 32 eyes with developmental cataract achieved a visual acuity of $6 / 18$ or better. Marked anterior uveitis with pupillary membrane formation occurred in $9(13 \%)$ of the 67 eyes. Visually significant posterior capsule opacification occurred in 5 $(28 \%)$ of the 18 eyes with intact capsule. Our results demonstrate the suitability of IOL implantation in children from an area of low socioeconomic background, and suggest that IOL implantation is an effective and safe procedure for correction of paediatric aphakia. This may have implications for similar populations.
\end{abstract}

The management of cataract in the visually immature child poses unique problems. The need for prompt detection and management has been emphasised in preventing visual deprivation amblyopia. ${ }^{1}$ The introduction of sophisticated microsurgical instrumentation and the use of viscoelastic materials have enabled surgeons to remove cataracts and restore a clear visual axis early in the course of visual development without serious complications. However, visual rehabilitation to obtain clearly focussed images is essential. Contact lenses (CLs) have been

Correspondence to: Dr Charlie Kanawati, FRCS, FRCOphth, St John Ophthalmic Hospital, PO Box 19960, East Jerusalem, via Israel. Fax: (2)828327. the generally accepted method of optical correction,,$^{2-4}$ but they require considerable care and frequent lens loss leads to intermittent correction of aphakia. $^{4-7}$ These problems are magnified when socioeconomic reasons prevent even highly motivated parents from complying with traditional modes of visual rehabilitation. Intraocular lenses (IOLs) offer a permanent aphakic correction ${ }^{8,9}$ and allow easier treatment of amblyopia, ${ }^{6,10-11}$ as parents have only to concentrate on occlusion therapy.

The incidence of paediatric cataract in the Palestinian population of the West Bank and Gaza Strip is relatively high due to consanguineous marriages. ${ }^{12}$ St John Ophthalmic Hospital (SJOH) is the only effective unit providing ophthalmic care in the region. Previous attempts at visual rehabilitation following cataract surgery, using aphakic glasses and/ or CLs, have not been successful, due to the low socioeconomic conditions. Lack of parental awareness, particularly in rural areas and refugee camps, in addition to considerable travel restrictions in the Occupied Territories, often result in erratic patient follow-up. This report reviews the visual outcome and lens-induced complications of IOL implantation in children given the socioeconomic conditions that prevail in the West Bank and Gaza.

\section{PATIENTS AND METHODS}

\section{Patients}

Between September 1990 and December 1992, 98 children under 15 years of age underwent IOL implantation for non-traumatic cataract at $\mathrm{SJOH}$. Informed consent was obtained from the parents or guardians after detailed explanation of the advantages and disadvantages of the procedure and the possible treatment options. Only 40 patients were included in this study. The records of the remaining 58 either could not be recovered or had insufficient data as they had been operated on by other surgeons or followed up in clinics outside the hospital. Details on age, sex, area of origin, primary diagnosis, 


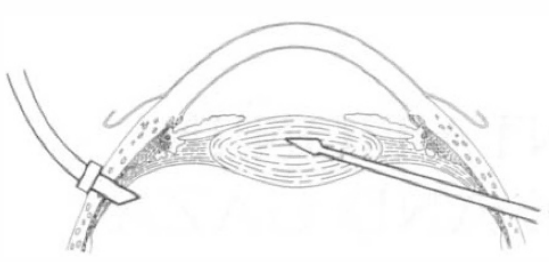

(a)

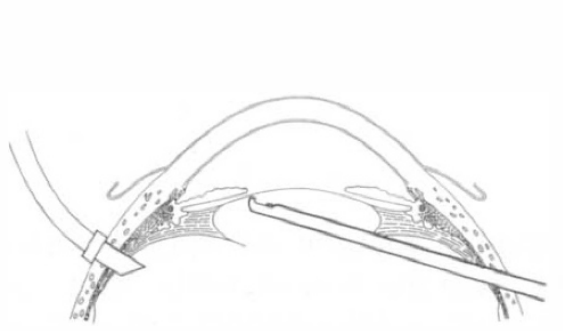

(d)

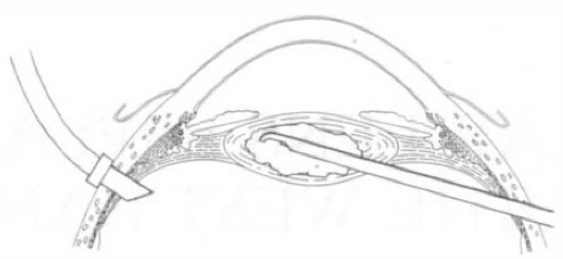

(b)

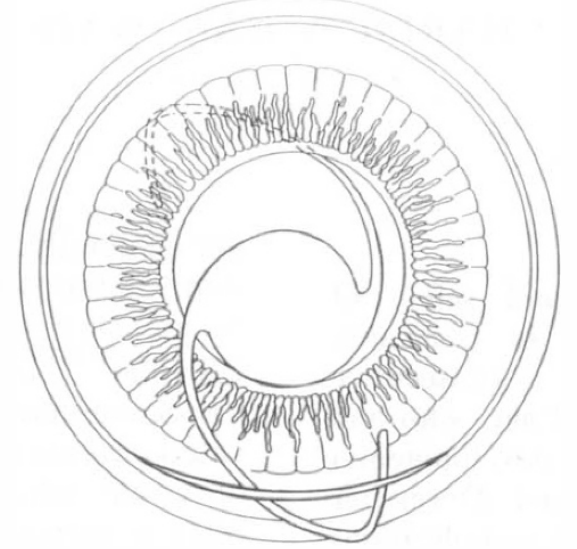

(e)

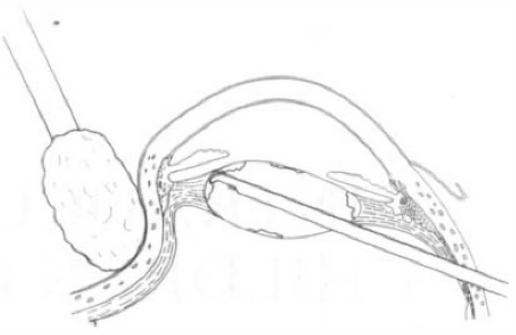

(c)

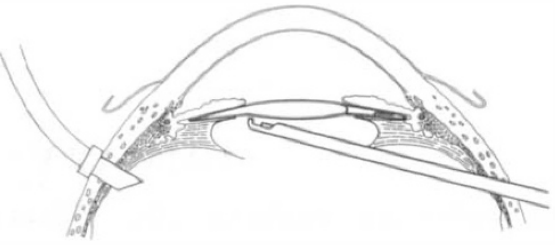

(f)

Fig. 1. Diagrammatic representation of the two-port pars plicata lens aspiration technique. One sclerotomy is used for fluid infusion and the other for the vitreous cutter. After complete aspiration of lens matter with scleral depression, central posterior capsulectomy is performed followed by an anterior vitrectomy. The anterior capsule is polished with the vitreous cutter tip using gentle suction. The vitreous cutter entry site is temporarily closed and a 6-7 mm corneoscleral incision is made for placement of a PC IOL in front of the anterior capsule. After closure of the limbal incision a central anterior capsulectomy of 4-6 $\mathrm{mm}$ diameter is created with the ocutome through the pars plicata.

perinatal and family history, associated systemic disorders, pre-operative visual acuity and ocular examination, procedure performed, post-operative amblyopia treatment, and outcome of surgery in terms of visual results, refraction and complications were obtained. These are shown in Tables I-IV. Differentiation between congenital and developmental cataract was based on the presence or absence of cataract at birth. Prior to the study period children with significant lens opacities had cataract surgery and correction with aphakic glasses or CLs. Those with only partial lens opacification and reasonable vision were followed up using mild mydriatic drops (tropicamide $0.5 \%$ ). During the study period patients presenting with cataract had correction with primary IOLs. Slit lamp biomicroscopy, direct and indirect ophthalmoscopy and A- and B-mode ultrasonography were carried out on all cases. Pre-operative and post-operative visual acuities were assessed where possible by a method consistent with the child's age and ability.

\section{Intraocular Lenses}

One-piece PMMA Sinskey-type posterior chamber (PC) IOLs were used in all cases. IOL power was calculated using the SRK formula on the basis of the axial length (A-scan) and keratometric readings when possible. An IOL was selected to achieve emmetropia in children over 3 years and undercorrection by 2-3 dioptres in younger children, in the expectation of myopic shift with age due to growth of the eyeball. ${ }^{13}$ In cases of unilateral cataract, adjustment of IOL power was made to match the other eye, to prevent marked post-operative anisometropia.

\section{Surgical Technique}

Over the period of the study, the surgical technique changed out of necessity and experience. All cases in this series were performed by one surgeon (C.A.K.). Prior to all operations the pupils were dilated intensively with phenylephrine $2.5 \%$ and cyclopentolate $0.5-1 \%$ eyedrops. Pupil dilatation throughout the procedure was maintained by addition of $0.5 \mathrm{ml}$ adrenaline (1/1000) to the $500 \mathrm{ml}$ bag of Hartmann's solution.

Fifteen eyes of 8 children underwent a two-port pars plicata lens aspiration and anterior vitrectomy procedure (Fig. 1). One sclerotomy was used for intraocular fluid infusion and the other for the vitreous cutter. After complete lens aspiration, aided with scleral depression to remove peripheral cortical lens matter, a central posterior capsulectomy was created with the vitreous cutter. However, to 


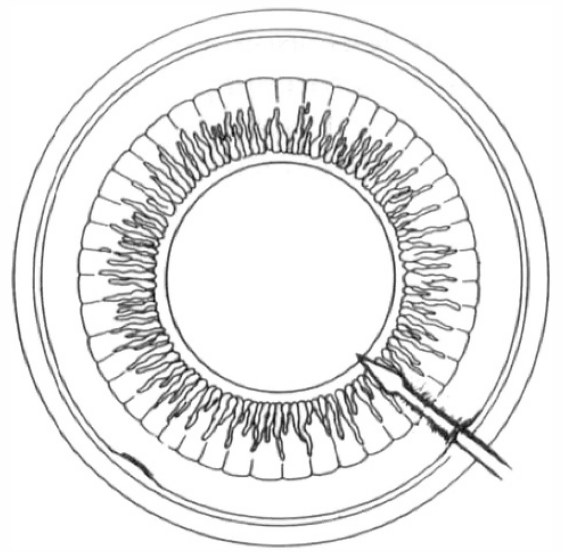

(a)

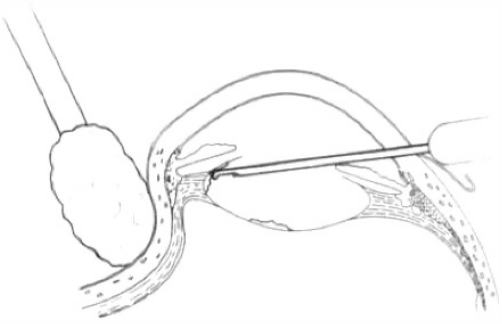

(d)

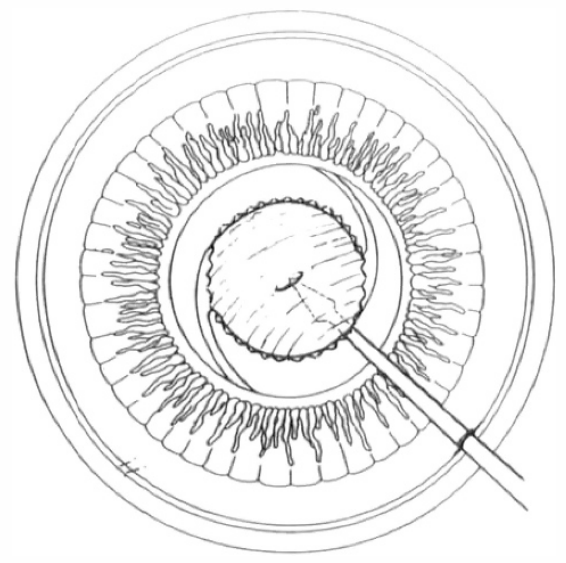

(g)

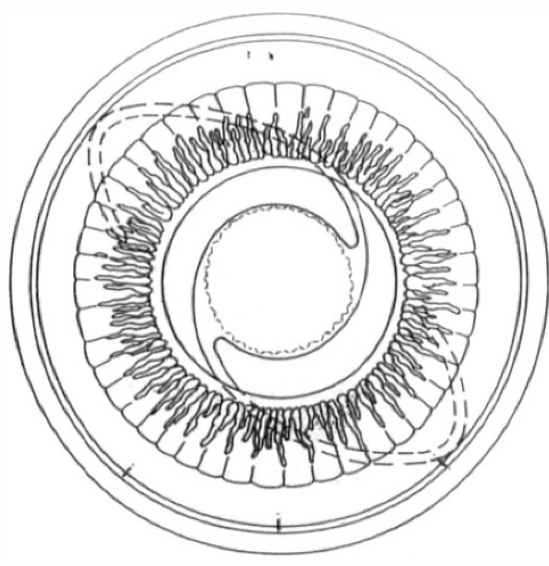

(j)
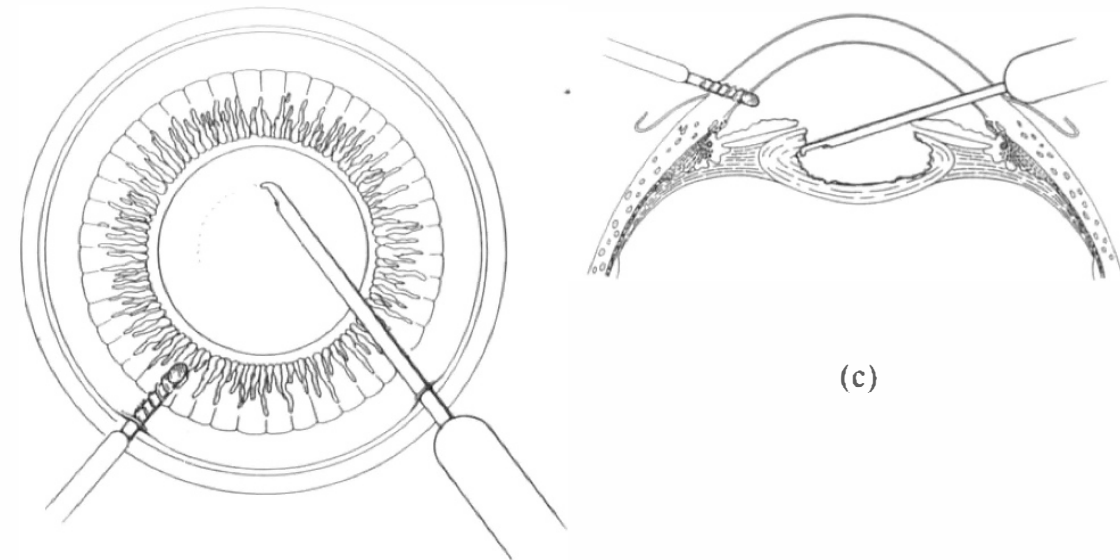

(c)

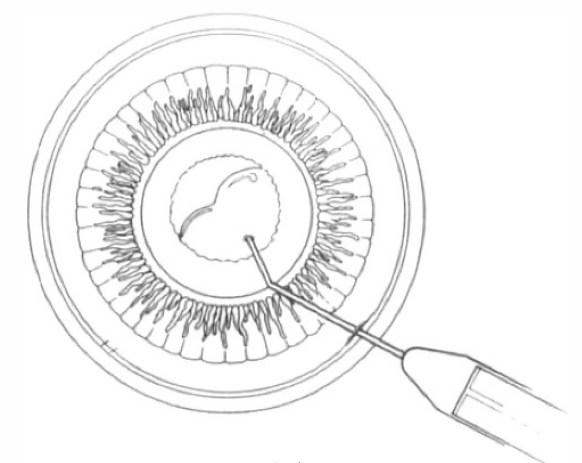

(e)

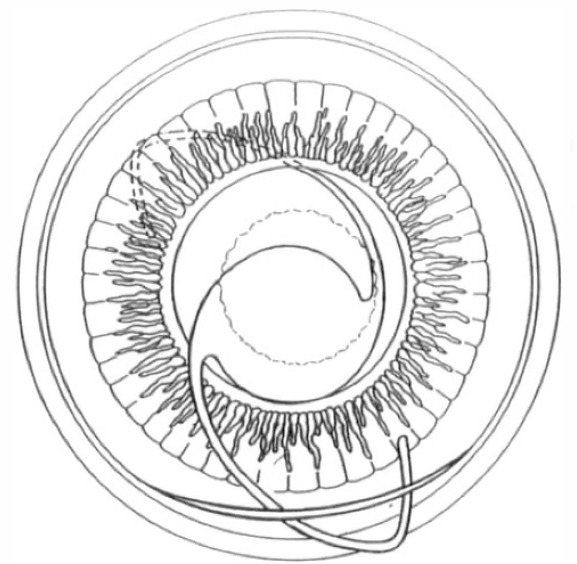

(f)

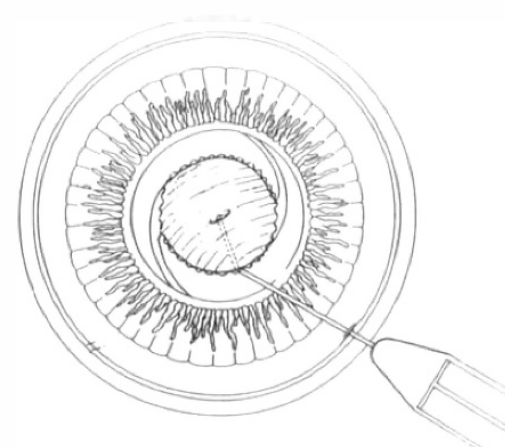

(h)

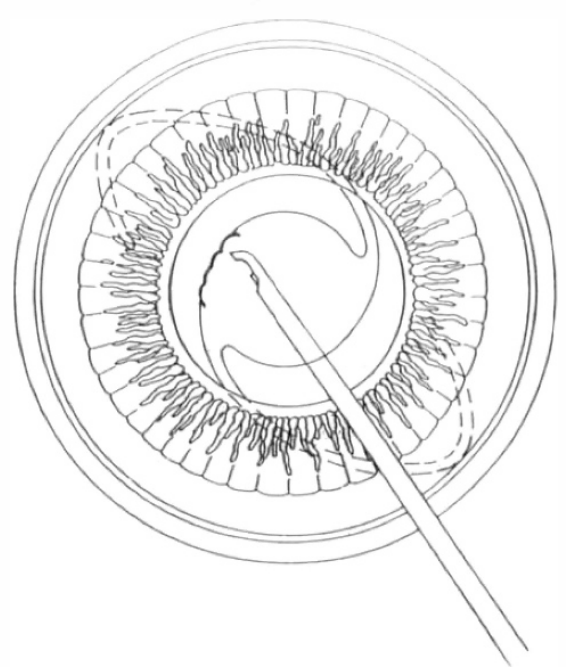

(i)

Fig. 2. Diagrammatic representation of the limbal lens aspiration technique. Two 20-gauge limbal incisions are made with an MVR blade. A central anterior capsulectomy of $4-6 \mathrm{~mm}$ diameter is performed using the vitreous cutter. Complete aspiration of lens matter with scleral depression is carried out with the vitreous cutter. The anterior chamber is maintained with Hartmann's solution through a selfretaining cannula. One of the incisions is extended to 6-7 $\mathrm{mm}$ to enable placement of a PC IOL in the capsular bag. In selected cases the posterior capsule is breached with an MVR blade under the IOL and a small amount of HPMC $2 \%$ is injected under the capsule to push back the intact hyaloid face. A central posterior capsulectomy is then carefully created with the vitreous cutter under minimal cutting rate and aspiration power. 
facilitate IOL implantation in the posterior chamber the anterior capsule was preserved and polished with a capsule polisher and/or the vitreous cutter tip with gentle suction (13 eyes). The vitreous cutter entry site was then closed with a plug and a 6-7 mm corneoscleral incision was made. A PC IOL was placed in front of the anterior capsule with the haptics in the ciliary sulcus using hydroxypropyl methylcellulose (HPMC) $2 \%$ as the viscoelastic material. Following closure of the corneoscleral wound with three or four interrupted 10-0 nylon sutures, a central capsulectomy of 4-6 mm diameter was created with the vitreous cutter through the pars plicata incision. The sclerotomies were closed with 7-0 vicryl. The patient with Marfan's syndrome and subluxed lenses had sutured sulcus-fixated PC IOLs implanted via a corneoscleral incision after pars plicata lensectomy.

Fifty-two eyes of 32 children underwent limbal lens aspiration (Fig. 2). Two 20-gauge limbal incisions were made with an MVR blade in the 10 and 2 o'clock meridians. A central anterior capsulectomy was performed using the vitreous cutter. Lens aspiration was carried out with the vitreous cutter using aspiration with or without cutting through one of the incisions, together with a simultaneous anterior chamber Hartmann solution infusion through a self-retaining cannula in the other incision. The vitreous cutter and cannula were interchanged as required to remove most of the lens matter. Following complete lens matter removal, aided with indentation with a cotton bud when necessary, one of the incisions was closed with 10-0 monofilament nylon suture and the other incision extended to 6-7 $\mathrm{mm}$ to enable the placement of a PC IOL in the capsular bag, or the ciliary sulcus when that was not possible, using HPMC $2 \%$ as the viscoelastic material. In children under 5 years of age and in cases with large thick posterior capsule plaques the posterior capsule was then breached with an MVR blade under the IOL and a small amount of HPMC $2 \%$ injected through the opening to push back the intact anterior hyaloid face. A central posterior capsulectomy of 4-6 mm diameter was carefully created with the vitreous cutter under minimal cutting rate and aspiration power. In older children the posterior capsule was left intact and dealt with post-operatively when opacification occurred. The corneoscleral wound was closed with three or four interrupted 10-0 monofilament nylon sutures and the knots were buried.

In children with bilateral cataracts the two eyes were operated on simultaneously or within a few days of each other depending on the anaesthetic status. The first eye was occluded continuously to prevent any advantage over the second eye. Four eyes underwent secondary PC IOL implantation a few months after limbal lens aspiration and CL failure. At the end of all procedures gentamicin sulphate $(20 \mathrm{mg})$ and betamethasone sodium phosphate $(3 \mathrm{mg})$ were given subconjunctivally.

\section{Post-operative Management}

Topical treatment of combined dexamethasone $0.1 \%$, chloramphenicol $0.5 \%$ and Polymyxin B sulphate hourly and cyclopentolate $0.5-1 \%$ twice daily were given for the first week and were reduced over the next 8-10 weeks according to the ocular inflammatory response. In no case was anti-inflammatory therapy needed for more than 10 weeks. This regime was modified in children who developed marked post-operative fibrinous uveitis (Tables I, III, IV). In children who developed posterior capsular thickening Nd:YAG laser posterior capsulotomy was carried out under topical anaesthesia with or without a CL.

Amblyopia treatment, tailored to each patient, was initiated and enforced by the orthoptists and the nursing staff on the first post-operative day and maintenance amblyopia treatment was continued as needed under orthoptic supervision. Total occlusion of the fixing eye part time (range 3 hours to half the waking hours in a day) was carried out with reasonable success, depending on the age of the child and the density of amblyopia. At each followup visit fixation preference and visual acuity were recorded to monitor and modify occlusion therapy. All pre-operative and post-operative visual acuities were assessed by the same method depending on the age and the ability of the child. From birth to 6 months of age, cover test observations and fixation preference and steadiness were used. From 6 months to 2 years of age, visual acuities were tested with the Catford Drum (already correlates to Snellen's equivalents), 'Hundreds and Thousands' cake decorations (if seen at $1 / 3$ metre $=6 / 12$ ), and larger cake decorations $(3 \mathrm{~mm}$ size if seen at $1 / 3$ metre $=6 / 60)$. Kay pictures were used for children aged 2-5 years and the Sonsken Silver visual acuity test for children aged 5-7 years. In children aged 7 years and older Snellen's chart (with or without matching card) or an Arabic number chart were used. The preferential looking method was not available at our orthoptic department during the study period.

The sutures were removed $8-10$ weeks postoperatively and retinoscopy was carried out at the same time. Spectacles or low-power CLs were prescribed for residual ametropia when needed. Bifocal spectacles were prescribed for a few children of school age. Compliance with post-operative spectacles and CLs was poor due to cultural reasons and the prevailing low socioeconomic conditions. Follow-up over a period of 12 months to 3.2 years (mean 2.3 years) was carried out weekly for 3 weeks, 
2 weekly for 3 months and then as required for orthoptic treatment. At each visit occlusion therapy was monitored and a complete ocular examination was performed and any complications were treated as detailed in Tables I, III and IV.

\section{RESULTS}

For reasons of clarity, and since visual deprivation amblyopia has different effects, the results were analysed in the following subgroups: unilateral congenital, unilateral developmental, bilateral congenital and bilateral developmental cataracts (Tables I-IV) and finally the overall results were presented. For purposes of quantitative estimation of absolute acuity levels and to calculate the change in acuity between pre- and post-operative assessment, acuity estimates recorded at less than the standard $6 \mathrm{~m}$ distance were converted to the standard distance. Acuity assessment recorded as perception of light only or unrecordable was taken as $6 / 360$. Further, the visual acuities were converted to octaves (one octave is roughly equivalent to 2 Snellen lines), to compare improvements in post-operative acuities.

\section{Unilateral Congenital Cataracts (UCC)}

Seven children, age range 1-36 months (mean 18 months), were included in this subgroup with a follow-up period of 12-24 months (mean 19 months) (Table I). All children showed an improvement in visual acuity (VA) from pre-operative levels. There was an improvement in acuity of 3-4.5 octaves (mean 3.6 octaves). Children aged 12 months and older at the time of surgery achieved a final VA of 6/36-6/24 and the child (N1) who had surgery at the age of 1 month achieved a VA of $6 / 18$. Two children (N1 and N2) developed marked fibrinous iritis with formation of a pupillary membrane but responded quite well to one or two subconjunctival injections of betamethasone and mydricaine and intensive topical steroid therapy. The inflammation resolved without any sequelae. All patients in this subgroup had preoperative esotropia in the affected eye which improved remarkably post-operatively. In one patient (N6) the operated eye was slightly microphthalmic, and another patient (N2) had a persistent hyaloid artery. The lens opacities in this subgroup were partial except for one case (N1) with total lens opacity and one (N2) with moderately dense lens opacity. One patient had a significant post-operative anisometropia requiring +6.5 dioptres overcorrection with a contact lens at 2 months post-surgery. This was probably due to errors in IOL calculation.

\section{Unilateral Developmental Cataracts (UDC)}

Six children, age range 11-15 years (mean 13.5 years), were included in this subgroup with a followup of 18-38 months (mean 31 months) (Table II). Acuity improved in all children, by $2.5-3.5$ octaves (mean 3.0 octaves). Five achieved a final VA of 6/12 or better and 1 (N5) a VA of 6/24 due to deep amblyopia. There were no associated ocular problems, in contrast to the unilateral congenital cataract subgroup, and this may be one of the main reasons for a significant improvement in acuity levels. There were no serious post-operative complications. One

Table I. Unilateral congenital cataracts subgroup: clinical data

\begin{tabular}{|c|c|c|c|c|c|c|c|c|}
\hline $\begin{array}{l}\text { Patient no. } \\
\text { (N) }\end{array}$ & $\begin{array}{l}\text { Age at } \\
\text { surgery } \\
\text { (months) } \\
{[\text { mean }=19]}\end{array}$ & $\begin{array}{l}\text { Involved } \\
\text { eye }\end{array}$ & $\begin{array}{l}\text { Associated } \\
\text { ocular problems }\end{array}$ & $\begin{array}{l}\text { Pre-op. } \\
\text { VA }\end{array}$ & $\begin{array}{l}\text { Post-op. } \\
\text { VA }\end{array}$ & $\begin{array}{l}\text { Follow-up } \\
\text { period } \\
\text { (months) } \\
{[\text { mean }=19]}\end{array}$ & Complications & Management \\
\hline 1 & 1 & $\mathrm{R}$ & RET & $6 / 360$ & $6 / 18$ & 24 & $\begin{array}{l}\text { Fibrinous uveitis } \\
\text { and formation of } \\
\text { pupillary } \\
\text { membrane }\end{array}$ & $\begin{array}{l}\text { Intensive steroid } \\
\text { drops; } \\
\text { subconjunctival } \\
\text { steroid + } \\
\text { mydricaine; } \\
\text { resolved }\end{array}$ \\
\hline 2 & 12 & $\mathrm{R}$ & $\begin{array}{l}\text { RET, persistent } \\
\text { hyaloid artery }\end{array}$ & $6 / 180$ & $6 / 24$ & 20 & $\begin{array}{l}\text { Fibrinous uveitis } \\
\text { and formation of } \\
\text { pupillary } \\
\text { membrane }\end{array}$ & $\begin{array}{l}\text { Intensive steroid } \\
\text { drops; } \\
\text { subconjunctival } \\
\text { steroid + } \\
\text { mydricaine; } \\
\text { resolved }\end{array}$ \\
\hline 3 & 14 & $\mathbf{R}$ & RET & $6 / 360$ & $6 / 36$ & 13 & - & - \\
\hline 4 & 18 & $\mathrm{R}$ & RET & $6 / 120$ & $6 / 24$ & 20 & - & - \\
\hline 5 & 24 & $\mathbf{R}$ & RET & $6 / 360$ & $6 / 36$ & 12 & - & - \\
\hline 6 & 28 & $\mathrm{~L}$ & $\begin{array}{l}\text { LET, } \\
\text { microphthalmos }\end{array}$ & $6 / 360$ & $6 / 24$ & 24 & - & - \\
\hline 7 & 36 & $\mathrm{~L}$ & LET & $6 / 360$ & $6 / 24$ & 20 & - & - \\
\hline
\end{tabular}

VA, visual acuity; R, right; L, left; ET, esotropia.

Male:female ratio $4: 3$.

Degree of esotropia improved remarkably in all children post-operatively.

All pre-operative and post-operative VAs were assessed by the same method depending on the age and ability of the child.

Limbal lens aspiration, PC IOL and central posterior capsulectomy: N1-N5, N7.

Pars plicata lens aspiration, anterior vitrectomy, PC IOL and central anterior capsulectomy: N6. 
Table II. Unilateral developmental cataracts subgroup: clinical data

\begin{tabular}{|c|c|c|c|c|c|c|}
\hline Patient no. (N) & $\begin{array}{l}\text { Age at } \\
\text { surgery (years) } \\
{[\text { mean }=13.5]}\end{array}$ & Involved eye & Pre-op. VA & Post-op. VA & $\begin{array}{l}\text { Follow-up } \\
\text { period (months) } \\
{[\text { mean }=31]}\end{array}$ & $\begin{array}{l}\text { Other surgical } \\
\text { procedures }\end{array}$ \\
\hline 1 & 11 & $\mathrm{~L}$ & $6 / 60$ & $6 / 12$ & 30 & - \\
\hline 2 & 12 & $\mathrm{~L}$ & $6 / 60$ & $6 / 9$ & 34 & - \\
\hline 3 & 14 & $\mathbf{R}$ & $6 / 36$ & $6 / 6$ & 38 & - \\
\hline 4 & 14 & $\mathbf{R}$ & $6 / 120$ & $6 / 12$ & 36 & - \\
\hline 5 & 15 & $\mathbf{R}$ & $6 / 240$ & $6 / 24$ & 18 & $\begin{array}{l}\text { Nd:YAG laser } \\
\text { capsulotomy } 3 \text { months } \\
\text { post-op. }\end{array}$ \\
\hline 6 & 15 & $\mathbf{R}$ & $6 / 60$ & $6 / 9$ & 30 & - \\
\hline
\end{tabular}

VA, visual acuity; $R$, right; $L$, left.

Male:female ratio $4: 2$.

All pre-operative and post-operative VAs were assessed with standard Landolt C chart.

All cataracts were removed by the limbal lens aspiration procedure.

There were no associated ocular problems, and no complications.

child (N5) required YAG capsulotomy 3 months after surgery.

\section{Bilateral Congenital Cataracts (BCC)}

Fourteen children, age range 1.5-36 months (mean
18.2 months), were followed up for a mean of 25.2 months (range 21-32 months) (Table III). A mean improvement in acuity of 3.1 octaves for the right eye and 2.9 octaves for the left eye indicated significant improvement in this subgroup. Sixteen of 28 eyes

Table III. Bilateral congenital cataracts subgroup: clinical data

\begin{tabular}{|c|c|c|c|c|c|c|c|c|c|c|}
\hline \multirow[b]{2}{*}{$\begin{array}{l}\text { Patient } \\
\text { no. }(\mathrm{N})\end{array}$} & \multirow{2}{*}{$\begin{array}{l}\text { Age at } \\
\text { surgery } \\
\text { (months) } \\
{[\text { mean }=18.2 \text { ] }}\end{array}$} & \multirow{2}{*}{$\begin{array}{l}\text { Associated } \\
\text { ocular } \\
\text { problems }\end{array}$} & \multicolumn{2}{|l|}{$\mathrm{R}$} & \multicolumn{2}{|l|}{$\mathrm{L}$} & \multirow{2}{*}{$\begin{array}{l}\text { Follow-up } \\
\text { period } \\
\text { (months) } \\
\text { [mean }=25.2 \text { ] }\end{array}$} & \multirow[b]{2}{*}{ Complications } & \multirow[b]{2}{*}{ Management } & \multirow[b]{2}{*}{$\begin{array}{l}\text { Other surgical } \\
\text { procedures }\end{array}$} \\
\hline & & & $\begin{array}{l}\text { Pre-op. } \\
\text { VA }\end{array}$ & $\begin{array}{l}\text { Post-op. } \\
\text { VA }\end{array}$ & $\begin{array}{l}\text { Pre-op. } \\
\text { VA }\end{array}$ & $\begin{array}{l}\text { Post-op. } \\
\text { VA }\end{array}$ & & & & \\
\hline 1 & 1.5 & Nystagmus & $6 / 360$ & $6 / 36$ & $6 / 360$ & $6 / 36$ & 21 & $\begin{array}{l}\text { Fibrinous } \\
\text { uveitis }+ \\
\text { formation of } \\
\text { pupillary } \\
\text { membrane } \\
(\mathrm{R}+\mathrm{L})\end{array}$ & $\begin{array}{l}\text { Intensive } \\
\text { steroid drops; } \\
\text { subconjunctival } \\
\text { steroid + } \\
\text { mydricaine } \\
(\mathrm{R}+\mathrm{L}) \text {; resolved }\end{array}$ & - \\
\hline 2 & 4 & Nystagmus & $6 / 360$ & $6 / 36$ & $6 / 360$ & $6 / 24$ & 24 & - & - & - \\
\hline
\end{tabular}

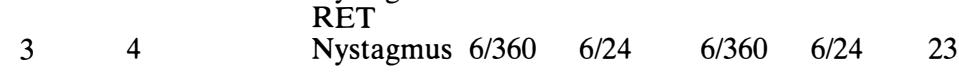

$\begin{array}{lr}4 & 5 \\ 5 & 6 \\ 6 & 12 \\ 7 & 12 \\ 8 & 16\end{array}$

$9 \quad 24$

$\begin{array}{clllll}\text { Nystagmus } & 6 / 360 & 6 / 24 & 6 / 360 & 6 / 24 & 21 \\ \text { Nystagmus } & 6 / 360 & 6 / 18 & 6 / 360 & 6 / 18 & 27 \\ \text { Nystagmus } & 6 / 360 & 6 / 24 & 6 / 360 & 6 / 24 & 22 \\ \text { Nystagmus } & 6 / 240 & 6 / 18 & 6 / 240 & 6 / 18 & 26 \\ & 6 / 24 & 6 / 18 & 6 / 24 & 6 / 18 & 21 \\ \text { with } & & \text { with } & & \\ \text { CL } & & \text { CL } & & \\ \text { 6/60 } & 6 / 18 & 6 / 60 & 6 / 18 & 30\end{array}$

$6 / 60 \quad 6 / 18$

$6 / 60 \quad 6 / 18 \quad 30$
RET

\begin{tabular}{|c|c|c|c|c|c|c|}
\hline 30 & RET & $6 / 360$ & $6 / 36$ & $6 / 36$ & $6 / 12$ & 2 \\
\hline 32 & & $\begin{array}{l}6 / 36 \\
\text { with } \\
\text { CL }\end{array}$ & $6 / 18$ & $\begin{array}{l}6 / 36 \\
\text { with } \\
\text { CL }\end{array}$ & $6 / 18$ & 2 \\
\hline 36 & & $6 / 60$ & $6 / 9$ & $6 / 60$ & $6 / 9$ & 3 \\
\hline 36 & & $6 / 60$ & $6 / 12$ & $6 / 60$ & $6 / 12$ & 3 \\
\hline 36 & Nysta & $6 / 180$ & $6 / 36$ & $6 / 60$ & $6 / 18$ & 2 \\
\hline
\end{tabular}

Fibrinous Intensive steroid Synechiolysis + uveitis + formation of posterior synechiae and mydricaine (L); decentred IOL resolved

(L)

$\begin{array}{ll}- & - \\ - & - \\ - & -\end{array}$

Fibrinous Intensive uveitis $+\quad$ steroid drops; : formation of subconjunctival pupillary steroid + membrane mydricaine $(\mathrm{R}+\mathrm{L}) \quad(\mathrm{R}+\mathrm{L})$; resolved -

VA, visual acuity; R, right; L, left; ET, esotropia; CL, contact lens.

Male:female ratio 9:5.

Pars plicata lens aspiration, anterior vitrectomy, PC IOL and central anterior capsulectomy: N5, N6, N9, N12, N13.

Limbal lens aspiration, PC IOL and central posterior capsulectomy: N1-N4, N7, N10, N14.

Limbal lens aspiration at age 2 months: N8; and age 5 months: N11.

Socondary PC IOL and central posterior capsulectomy: N8, N11.

All pre-operative and post-operative VAs were assessed by the same method according to the child's ability and age. 
Table IV. Bilateral development cataracts subgroup: clinical data

\begin{tabular}{|c|c|c|c|c|c|c|c|c|c|c|}
\hline \multirow[b]{2}{*}{$\begin{array}{l}\text { Patient } \\
\text { no. }(\mathrm{N})\end{array}$} & \multirow{2}{*}{$\begin{array}{l}\text { Age at } \\
\text { surgery } \\
\text { (months) } \\
{[\text { mean = 7.4] }}\end{array}$} & \multirow{2}{*}{$\begin{array}{l}\text { Associated } \\
\text { ocular } \\
\text { problems }\end{array}$} & \multicolumn{2}{|l|}{$\mathrm{R}$} & \multicolumn{2}{|l|}{$\mathrm{L}$} & \multirow{2}{*}{$\begin{array}{l}\text { Follow-up } \\
\text { period } \\
\text { (months) } \\
{[\text { mean }=31.8 \text { ] }}\end{array}$} & \multirow[b]{2}{*}{ Complications } & \multirow[b]{2}{*}{ Management } & \multirow[b]{2}{*}{$\begin{array}{l}\text { Other surgical } \\
\text { procedures }\end{array}$} \\
\hline & & & $\begin{array}{l}\text { Pre-op. } \\
\text { VA }\end{array}$ & $\begin{array}{l}\text { Post-op. } \\
\text { VA }\end{array}$ & $\begin{array}{l}\text { Pre-op. } \\
\text { VA }\end{array}$ & $\begin{array}{l}\text { Post-op. } \\
\text { VA }\end{array}$ & & & & \\
\hline 1 & 4 & - & $6 / 60$ & $6 / 9$ & $6 / 360$ & $6 / 12$ & 27 & $\begin{array}{l}\text { Fibrinous } \\
\text { uveitis }+ \\
\text { formation of } \\
\text { pupillary } \\
\text { membrane } \\
(\mathrm{R}+\mathrm{L})\end{array}$ & $\begin{array}{l}\text { Intensive } \\
\text { steroid drops; } \\
\text { subconjunctival } \\
\text { steroid, + } \\
\text { mydricaine } \\
(\mathrm{R}+\mathrm{L}) \text { resolved }\end{array}$ & - \\
\hline 2 & 4 & - & $6 / 60$ & $6 / 12$ & $6 / 60$ & $6 / 12$ & 29 & - & - & - \\
\hline 3 & 4 & $\begin{array}{l}\text { Nystagmus } \\
\text { (hydro- } \\
\text { cephalus) }\end{array}$ & $6 / 180$ & $6 / 24$ & $6 / 180$ & $6 / 24$ & 30 & - & - & - \\
\hline 4 & 4 & $\begin{array}{l}\text { LET, } \\
\text { nystagmus }\end{array}$ & $6 / 60$ & $6 / 6$ & $6 / 360$ & $6 / 24$ & 37 & - & - & - \\
\hline 5 & 4 & - & $6 / 180$ & $6 / 18$ & $6 / 180$ & $6 / 18$ & 29 & $\begin{array}{l}\text { Fibrinous } \\
\text { uveitis }+ \\
\text { formation of } \\
\text { pupillary } \\
\text { membrane } \\
(\mathrm{R}+\mathrm{L})\end{array}$ & $\begin{array}{l}\text { Intensive } \\
\text { steroid drops; } \\
\text { subconjunctival } \\
\text { steroid + } \\
\text { mydricaine } \\
(\mathrm{R}+\mathrm{L}) ; \\
\text { resolved }\end{array}$ & - \\
\hline 6 & 5 & - & $6 / 120$ & $6 / 24$ & $6 / 36$ & $6 / 9$ & 28 & - & - & - \\
\hline 7 & 6 & Nystagmus & $6 / 360$ & $6 / 36$ & $6 / 360$ & $6 / 36$ & 36 & - & - & $\begin{array}{l}\text { Nd:YAG laser } \\
\text { posterior } \\
\text { capsulotomy } 6 \\
\text { months post- } \\
\text { op. }(\mathrm{R}+\mathrm{L})\end{array}$ \\
\hline 8 & 8 & - & $6 / 60$ & $6 / 12$ & $6 / 60$ & $6 / 12$ & 31 & $\begin{array}{l}\text { Fibrinous } \\
\text { uveitis }+ \\
\text { formation of } \\
\text { pupillary- } \\
\text { membrane } \\
(\mathrm{R}+\mathrm{L})\end{array}$ & $\begin{array}{l}\text { Intensive } \\
\text { steroid + } \\
\text { mydriatic } \\
\text { drops; } \\
\text { Nd:YAG } \\
\text { laser mem- } \\
\text { branectomy } \\
\text { (R+L); resolved }\end{array}$ & \\
\hline 9 & 9 & $\begin{array}{l}\text { Subluxed } \\
\text { lenses } \\
\text { (Marfan's } \\
\text { syndrome) }\end{array}$ & $6 / 60$ & $6 / 18$ & $6 / 60$ & $6 / 18$ & 32 & - & - & $\begin{array}{l}\text { Sutured scleral- } \\
\text { fixated PC IOL } \\
(\mathrm{R}+\mathrm{L})\end{array}$ \\
\hline 10 & 10 & - & $6 / 60$ & $6 / 12$ & $6 / 60$ & $6 / 12$ & 30 & - & - & - \\
\hline 11 & 12 & - & $6 / 120$ & $6 / 12$ & $6 / 120$ & $6 / 9$ & 38 & - & - & \\
\hline 12 & 13 & - & $6 / 60$ & $6 / 12$ & $6 / 60$ & $6 / 9$ & 36 & - & - & $\begin{array}{l}\text { Nd:YAG laser } \\
\text { posterior } \\
\text { capsulotomy } 3 \\
\text { weeks post-op. } \\
(\mathrm{R}+\mathrm{L})\end{array}$ \\
\hline 13 & 13 & - & $6 / 36$ & $6 / 9$ & $6 / 60$ & $6 / 12$ & 30 & $\begin{array}{l}\text { Fibrinous } \\
\text { uveitis }+ \\
\text { formation of } \\
\text { pupillary } \\
\text { membrane (L) }\end{array}$ & $\begin{array}{l}\text { Intensive } \\
\text { steroid and } \\
\text { mydriatic } \\
\text { drops; } \\
\text { Nd:YAG } \\
\text { laser mem- } \\
\text { branectomy; } \\
\text { resolved (L) }\end{array}$ & \\
\hline
\end{tabular}

VA, visual acuity; $R$, right; L, left; ET, esotropia.

Male:female ratio 9:4.

Pars plicata lens aspiration, PC IOL and central anterior capsulectomy: N3.

Pars plicata lensectomy and sutured sulcus-fixated PC IOL: N9.

Limbal lens aspiration, PC IOL and central posterior capsulectomy: N1, N2, N4, N5, N6.

Limbal lens aspiration and PC IOL: N7, N8, N10, N11, N12, N13.

All pre-operative and post-operative VAs were assessed by the same method according to the child's ability and age.

achieved a final VA of $6 / 18$ or better, including 5 with a VA of $6 / 12$ or better. The remaining 12 eyes achieved a final VA of 6/36-6/24. The small improvement in vision in this group may be due to associated nystagmus, esotropia and poor compliance with amblyopia treatment. Nystagmus was detected in 8 patients (N1-N7, N14), and esotropia in $3(\mathrm{~N} 2, \mathrm{~N} 10, \mathrm{~N} 14)$. One patient (N4) had a residual 6 dioptres of hypermetropia that was corrected with $\mathrm{CL}$ at 2 months post-surgery. The 3 cases $(\mathrm{N} 1, \mathrm{~N} 3$, N9) of post-operative fibrinous iritis were managed as previously described, but one child (N3) required surgical intervention to divide posterior synechiae and reposition a decentred IOL 6 weeks after 
Table V. Final visual acuity in the congenital cataract group

\begin{tabular}{lccccc}
\hline Visual acuity & Age at surgery (months) & Mean follow-up (months) & No. of eyes & Unilateral group & Bilateral group \\
\hline $6 / 12-6 / 9$ & $30-36$ & 28.3 & 5 & 5 & 5 \\
$6 / 24-6 / 18$ & $1-36$ & 24.4 & 23 & 7 & 2 \\
$6 / 36$ & $14-36$ & 20.2 & 7 & 5 & 2 \\
\hline
\end{tabular}

primary implant surgery. Two patients had bilateral secondary PC IOL implants (N8, N11), 2 months and 5 months respectively after bilateral LLA and CL failure. Their vision improved from 6/24 and 6/36 respectively with CL to $6 / 18$ bilaterally with IOLs.

\section{Bilateral Developmental Cataracts (BDC)}

Thirteen children, mean age 7.4 years (range 4-13 years), were followed up for a range of 27-38 months (mean 31.8 months) (Table IV). VA improved by a mean of 2.8 octaves for the right eye and 3.0 octaves for the left eye. Twenty of 26 eyes achieved a final VA of $6 / 18$ or better, including 16 with a VA of $6 / 12$ or better. The remaining 6 eyes achieved a final VA of 6/36-6/24. Four children developed fibrinous iritis that resolved without sequelae with intensive steroid therapy (as described previously). In 3 eyes (N8 and N13) Nd:YAG laser was used to disrupt the inflammatory pupillary membrane. One child (N12) required bilateral $\mathrm{Nd}$ :YAG laser capsulotomy at 3 weeks and another (N7) at 6 months post-operatively. Three patients had nystagmus (N3, N4, N7), associated with hydrocephalus in one case (N3) and with esotropia in another (N4). In these patients the VA did not improve more than 6/24. One child (N9) had subluxated lenses (Marfan's syndrome) and sutured sulcus-fixated lenses were implanted without complications, achieving a final VA of $6 / 18$ in each eye.

\section{Post-operative Refractive Errors}

Retinoscopy at 8-10 weeks revealed low degrees of ametropia and astigmatism in most cases. One case (N7 of UCC group) required an overcorrection of +6.5 dioptres, and another case $(\mathrm{N} 4$ of $\mathrm{BCC}$ subgroup) required an overcorrection of +6.0 dioptres. In both cases CLs were used postoperatively with relatively good compliance.

Overall the visual results at the last examination in this series were encouraging (Tables V, VI). One of the reasons was definitely good compliance with occlusion therapy, as the parents had only to concentrate on that. Of the congenital cataract cases (35 eyes) $17(48.6 \%)$ achieved a final VA of $6 / 18$ or better, $28(80 \%)$ a VA of $6 / 24$ or better and 7
$(20 \%)$ a VA of $6 / 36$ (Fig. 3). In the developmental cataract cases (32 eyes) $25(78.1 \%)$ achieved a final VA of $6 / 18$ or better, $30(93.8 \%)$ a VA of $6 / 24$ or better and $2(6.2 \%)$ a VA of $6 / 36$ (Fig. 4$)$. Twenty-one $(65.6 \%)$ of 32 eyes with developmental cataract achieved a VA of $6 / 12$ or better compared with only $5(14.3 \%)$ of 35 eyes with congenital cataract. The best visual results were achieved in the developmental cataracts, followed by the bilateral congenital cataracts. The unilateral congenital cataracts had the lowest visual acuities and were the most difficult to manage because of the associated esotropia, late presentation and pre-existing deep amblyopia. However, there was a rewarding mean improvement in acuity of 3.6 octaves in this subgroup.

\section{DISCUSSION}

Paediatric pseudophakia remains a controversial subject. Although an anterior chamber lens implant in a child was reported by Choyce as early as $1958,{ }^{14}$ most paediatric ophthalmologists have been reluctant to implant IOLs in children due to reports of associated complications with earlier implant styles. $^{10,11}$ Concerns exist over the possibility of late-onset IOL-induced adverse effects and the problem of the dynamic changes in refractive power in early childhood.

Aphakic spectacles are impractical due to peripheral aberrations, constricted visual fields, aniseikonia in unilateral cases, weight and appearance. Although encouraging visual results have been reported by some, ${ }^{2-4}$ aphakic CLs require considerable ophthalmic care and are emotionally stressful.,6,15,16 Frequent $C L \operatorname{loss}^{4,5}$ is an economic burden to most children, particularly in deprived populations, and of more concern is the resultant intermittent correction of aphakia.

Epikeratophakia is not widely available and is expensive. Visual rehabilitation may be slow due to delayed corneal healing and is less successful in younger children than the initial reports indicated. ${ }^{17,18} \mathrm{~A}$ delay in amblyopia management due to slow healing of an epikeratophakia graft or to $\mathrm{CL}$

Table VI. Final visual acuity in the developmental cataract group

\begin{tabular}{lccccc}
\hline Visual acuity & Age at surgery (years) & Mean follow-up (months) & No. of eyes & Unilateral group & Bilateral group \\
\hline $6 / 12-6 / 6$ & $11-15$ & 32 & 21 & 5 & 1 \\
$6 / 24-6 / 18$ & $4-15$ & 29 & 9 & 2 & 1 \\
$6 / 36$ & 6 & 36 & 2 & 8 \\
\hline
\end{tabular}




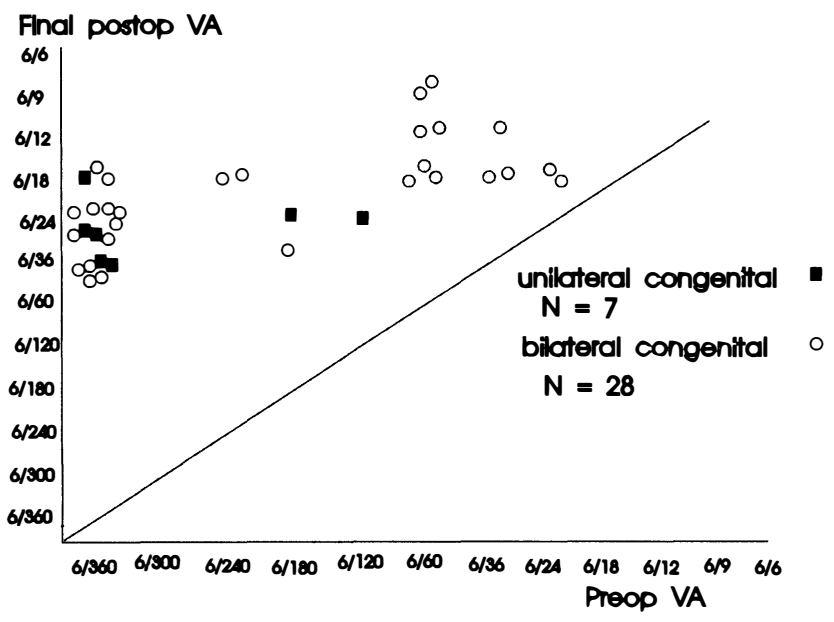

Fig. 3. Scattergram showing the pre-operative visual acuity plotted against the final acuity in the congenital cataract group. Circles and squares above and to the left of the diagonal represent eyes with improved vision.

problems could lead to irreversible deprivation amblyopia.

IOLs are superior to CLs in achieving satisfactory binocular function in adult unilateral aphakia ${ }^{19}$ and have the greatest potential for good uncorrected vision. The lens implant provides a stable retinal image with minimal or no aniseikonia in the unilateral aphakic patient ${ }^{20}$ and offers a permanent method of optical correction..$^{9}$ A recent study found no histopathological evidence that a child's eye tolerated an IOL less well than does an adult's. ${ }^{21}$ With a follow-up of 12 years, BenEzra ${ }^{22}$ reported no major lens-induced complications other than irregular pupil and sphincter and iris atrophy, in eyes with PC IOLs. The compliance with amblyopia treatment is better in children with IOLs than in those corrected with CLs as the emphasis is on amblyopia treatment and not on CL care. ${ }^{6,10}$ Ben Ezra and Rose $^{6}$ reported better VA, development of some peripheral fusion, smaller degrees of strabismus and more acceptable cosmetic appearance in pseudophakic eyes compared with those corrected with CLs.

The visual results in this series were encouraging (Tables V, VI). One of the important reasons was the fairly good compliance with amblyopia treatment. The best visual results were achieved in the subgroup with developmental cataracts (as found in previous reports ${ }^{8,20,23,24}$ ), followed by the bilateral congenital cataract subgroup. The unilateral congenital cataracts had the least good VAs and were the most difficult to manage due to the associated esotropia, late presentation and pre-existing deep amblyopia. However, even so, there was a rewarding mean improvement in acuity of 3.6 octaves in this subgroup. Without treatment these children may have acuities of perception of light only. ${ }^{25}$ One would expect the acuities in the bilateral congenital cataracts to be better; however, in this series, the

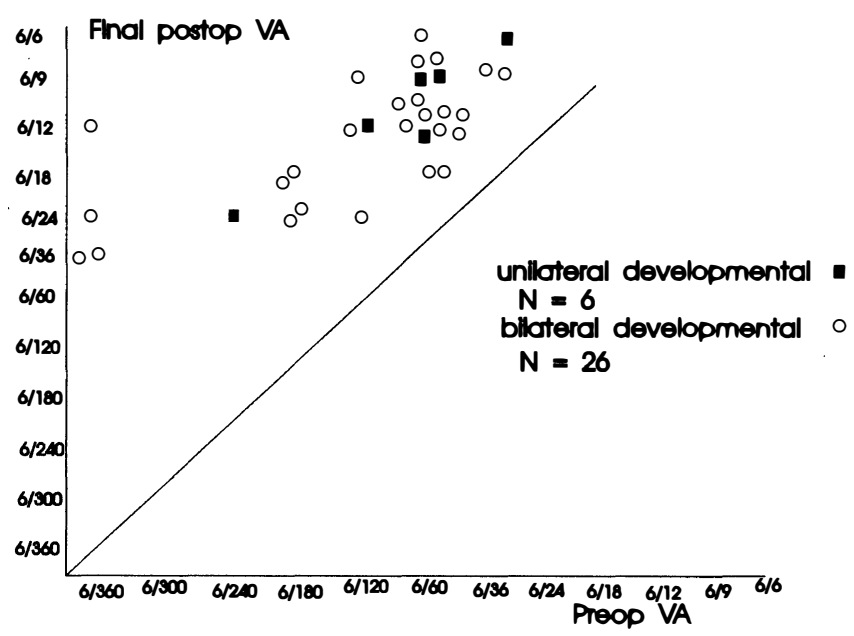

Fig. 4. Scattergram showing the pre-operative visual acuity plotted against the final acuity in the developmental cataract group. Circles and squares above and to the left of the diagonal represent eyes with improved vision.

high incidence of nystagmus and esotropia and late presentation with its resulting deeper amblyopia worsened the prognosis. Older patients in this subgroup achieved better visual results, probably because their lens opacities were only partial at birth and they had been using mydriatic drops under close orthoptic supervision prior to surgery. As in other reports ${ }^{6}$ in the majority of cases with pre-existing esotropia in this series the degree of strabismus was markedly reduced post-operatively.

IOLs were well tolerated and there were no major complications in this series. The most common early post-operative complication was a more marked anterior uveitis and formation of pupillary membrane in $9(13.4 \%)$ of 67 eyes. Visually significant posterior capsule opacification occurred in $5(27.7 \%)$ of 18 eyes with preserved capsule. Significant IOL decentration and posterior synechiae were observed in one case. This was treated successfully with surgical intervention 6 weeks after primary implant surgery. A few patients exhibited mild iridolenticular synechiae and pigmented precipitates on the surface of the lens implant that persisted after cessation of topical steroids, particularly those who were not using the drops correctly. Some developed later sphincter and iris atrophy. The low rate of complications in this series could be related to the selection of patients, complete aspiration of the lens matter, polishing of the capsule, lens type and particularly good control of the inflammatory response.

Fibrinous anterior uveitis is a common postoperative complication in children that may lead to central posterior synechiae, pupillary block glaucoma and retrolenticular opaque membrane formation. $6,8,23,24,30,33$ In this series intensive topical steroids and aggressive dilation of the pupils were used as soon as any sign of inflammation, even minimal ciliary injection, ${ }^{23}$ was observed. Topical 
cycloplegic/mydriatics are necessary to prevent the formation of posterior synechiae and to reduce the chance of pupillary block. The inflammation responded remarkably well to medical treatment (Tables I, III, IV) in all cases with no major sequelae or effect on final VA. In addition to medical treatment 3 eyes in the bilateral developmental cataract subgroup required $\mathrm{Nd}$ :YAG laser to successfully disrupt inflammatory membranes. ${ }^{32}$

These patients confirm the view of Sinskey et al. ${ }^{23}$ that factors inducing more post-operative inflammation and its major sequelae include traumatic procedures, more iris manipulation and younger age of patients. The inflammation may be further reduced by using heparin surface modified PMMA lenses, ${ }^{26}$ or poly HEMA IOLs. ${ }^{27}$ IOLs with polypropylene loops may not be biologically inert. ${ }^{28}$

Complete removal of the lens matter and avoidance of manipulation of the iris is recommended to reduce the stimulus for a marked inflammatory reaction post-operatively. Some of these cases were operated on by the pars plicata approach in order to reduce iris manipulation, remove the vitreous scaffold and to guarantee a permanently clear visual axis. ${ }^{8}$ Although post-operative inflammation was less frequent in these cases, the numbers in both groups were too small to draw conclusions. However, the limbal approach is preferred, in agreement with Sinskey et al., ${ }^{23}$ as the vitreous should not be disturbed unless it is absolutely necessary. No cases of cystoid macular oedema (CMO) occurred with either surgical approach, although fundus fluorescein angiography was not carried out. The technique changed with time as experience was gained and limbal lens aspiration was adopted as the preferred technique. Primary posterior capsulectomy following IOL implantation in children younger than 5 years was performed in order to provide a clear visual axis and to avoid the need for a second anaesthetic. In older children the posterior capsule was left intact to be dealt with when opacified post-operatively by $\mathrm{Nd}$ :YAG laser. In this experience, as in other reports, ${ }^{23,24,32}$ older children tolerated Nd:YAG laser capsulotomy well. An intact posterior capsule facilitates placement of the IOL in the bag and avoids vitreous incarceration in the cataract wound or vitreous adhesion to other anterior segment structures, with its well-recognised sequelae. Placement of a PC IOL in the bag and the use of one-piece PMMA biconvex designs probably reduces the frequency of posterior capsular opacification and inflammation. ${ }^{29}$

\section{CONCLUSION}

It is felt that, with the unique problems facing our population, IOL implantation for paediatric aphakia is a viable option. The results of this study indicate that PC IOL implantation is an effective means of correcting aphakia in children with unilateral and bilateral non-traumatic cataracts. Overall the postoperative visual acuities were excellent, refractive errors were acceptable, and there were no serious lens-induced complications. Although the long-term safety of paediatric IOL implantation is unknown, the ability of an IOL to provide a consistently stable retinal image, to eliminate anisometropia, and to improve our ability to prevent irreversible amblyopia are important practical considerations in the management of these patients. This may have implications for similar populations. This study supports the view of BenEzra ${ }^{22}$ that efforts should be concentrated on optimising the surgical techniques and developing better IOLs. Further studies are needed to develop methods of predicting the correct IOL power and post-operative refractive error.

I wish to thank Mr A. Chandna, FRCS, Alderhay Children Hospital, Liverpool, for his valuable comments and assistance in writing this paper. Also I thank Dr D. Broadbent, FRCS, St Paul's Eye Unit, Liverpool, and $\mathrm{Mr}$ M. Ward, FRCS, St John Ophthalmic Hospital, for revising the manuscript. I am grateful to Miss D. Magauran, FRCS, $\mathrm{Dr} \mathrm{H}$. Awad, and the nursing staff of SJOH for their help in the study. Mrs J. Musallam, DBO(D) and Miss D. Jones, DBO, Orthoptic Department, SJOH, were responsible for visual acuity assessment and amblyopia treatment. Miss G. Rycroft, Medical Illustration, Royal Liverpool University Hospital, drew the surgical techniques illustrations.

Key words: Amblyopia, Congenital cataract, Developmental cataract, Intraocular lenses, Paediatric aphakia, Surgery.

\section{REFERENCES}

1. Vaegan, Taylor D. Critical period for deprivation amblyopia in children. Trans Ophthalmol Soc UK 1979;99:432-9.

2. Nelson LB, Cutler SI, Calhoun JH, et al. Silsoft extended wear contact lenses in pediatric aphakia. Ophthalmology 1985;92:1529-31.

3. Holmstrom G, Speedwell L, Taylor D. Contact lenses: still the only solution for infant aphakia. Eur J Implant Refract Surg 1990;2:265-7.

4. Levin AV, Edmonds SA, Nelson LB, Calhoun JH, Harley RD. Extended-wear contact lenses for the treatment of pediatric aphakia. Ophthalmology 1988;95:1107-13.

5. Beller R, Hoyt CS, Marg E, Odom JV. Good visual function after neonatal surgery for congenital monocular cataracts. Am J Ophthalmol 1981;91:559-65.

6. BenEzra D, Rose L. Intraocular versus contact lenses for the correction of aphakia in unilateral congenital and developmental cataract. Eur J Implant Refract Surg 1990;2:303-7.

7. Hoyt CS. The optical correction of pediatric aphakia. Arch Ophthalmol 1986;104:651-2.

8. Dahan E, Welsh NH, Salmenson BD. Posterior chamber implants in unilateral congenital and developmental cataracts. Eur J Implant Refract Surg 1990;2:295-302.

9. Dahan E, Salmenson BD. Pseudophakia in children: 
precautions, technique, and feasibility. J Cataract Refract Surg 1990;16:75-82.

10. Binkhorst CD, Gobin MH. Treatment of congenital and juvenile cataract with intraocular lens implants (pseudophakos). Br J Ophthalmol 1970;54:759-65.

11. Binkhorst CD, Gobin MH. Congenital cataract and lens implantation. Ophthalmologica 1972;164:392-7.

12. Elder MJ, de Cock R. Childhood blindness in the West Bank and Gaza Strip: prevalence, aetiology and hereditary factors. Eye 1993;7:580-3.

13. Gordon RA, Donzis PB. Refractive development of the human eye. Arch Ophthalmol 1985;103:785-9.

14. Choyce DP. Correction of uniocular aphakia by means of anterior chamber acrylic implants. Trans Ophthalmol Soc UK 1958;78:459-70.

15. BenEzra D, Paez JH Congenital cataract and intraocular lenses. Am J Ophthalmol 1983;96:311-4.

16. Hiles DA. Intraocular lens implantation in children with monocular cataracts, 1974-1983. Ophthalmology 1984;91:1231-7.

17. Morgan KS, McDonald MB, Hiles DA, et al. The nationwide study of epikeratophakia for aphakia in children. Am J Ophthalmol 1987;103:366-74.

18. Morgan KS. Pediatric cataract and lens implantation. Curr Opin Ophthalmol 1994;5:55-60.

19. Katsumi O, Miyanaga Y, Hirose T, Okuno H, Asaoka I. Binocular function in unilateral aphakia. Ophthalmology 1988;95:1088-93.

20. Sinskey RM, Patel J. Posterior chamber intraocular lens implants in children: report of a series. J Am Intraocul Implant Soc 1983;9:157-60.

21. Reynolds JD, Hiles DA, Johnson BL, Biglan AW. A histopathological study of bilateral aphakia with a unilateral intraocular lens in a child. Am J Ophthalmol 1982;93:289-93.

22. BenEzra D. Intraocular lenses for unilateral paediatric aphakia: early lenses and long-term follow-up. Eur J Implant Refract Surg 1990;2:285-9.
23. Sinskey RM, Karel F, Dal Ri E. Management of cataracts in children. J Cataract Refract Surg 1989;15:196-200.

24. Burke JP, Willshaw HE, Young JDH. Intraocular lens implants for uniocular cataracts in childhood. $\mathrm{Br} \mathrm{J}$ Ophthalmol 1989;73:860-4.

25. Kushner BJ. Visual results after surgery for monocular juvenile cataracts of undetermined onset. Am J Ophthalmol 1986;102:468-72.

26. Borgioli DM, Coster DJ, Fan RFT, et al. Effect of heparin surface modification of polymethylmethacrylate intraocular lenses on signs of postoperative inflammation after extracapsular cataract extraction. Ophthalmology 1992;99:1248-55.

27. de Courten C, Bucher PJM, BenEzra D. Experience with HEMA lenses in paediatric cataract. Eur J Implant Refract Surg 1990;2:315-8.

28. Tuberville MA, Galin MA, Banda PD, et al. Complement activation by nylon and polypropylene-looped prosthetic intraocular lenses. Invest Ophthalmol Vis Sci 1982;22:727-33.

29. Martin RG, Sanders DR, Souchek J, Raanan MG, DeLuca M. Effect of posterior chamber intraocular lens design and surgical placement on postoperative outcome. J Cataract Refract Surg 1992;18:333-41.

30. Hiles DA, Hered RW. Modern intraocular lens implants in children with new age limitations. J Cataract Refract Surg 1987;13:493-7.

31. Markham RHC, Bloom PA, Chandna A, Newcomb $\mathrm{EH}$. Results of intraocular lens implantation in paediatric aphakia. Eye 1992;6:493-8.

32. Gimbel HV, Ferensowicz M, Raanan M, DeLuca M. Implantation in children. J Pediatr Ophthalmol Strabismus 1993;30:69-79.

33. Hiles DA, Watson BA. Complications of implant surgery in children. J Am Intraocul Implant Soc 1979;5:24. 